\title{
PREVALENCE OF TRAUMATIC DENTAL INJURIES AND THEIR RELATION WITH PREDISPOSING FACTORS AMONG 8-15 YEARS OLD SCHOOL CHILDREN OF INDORE CITY, INDIA
}

\author{
PREENE JUNEJA ${ }^{1}$, SADANAND KULKARNI ${ }^{1}$, SAPNA RAJE ${ }^{2}$
}

\author{
${ }^{1}$ Department of Pediatric and Preventive Dentistry, Sri Aurobindo College of \\ Dentistry, India \\ ${ }^{2}$ Department of Periodontics, Sri Aurobindo College of Dentistry, India
}

\begin{abstract}
Background. Dental injuries result in functional, esthetic and psychological disturbances accompanied by great concern from the child, the parent and the dentist. Oral injuries are fourth most common area of bodily injuries among 7-30 year-old individuals.

Aim. a) To assess the prevalence of traumatic dental injuries (TDI) and their relation with predisposing factors among 8-15 years old school children in Indore city, India.

b) To collect baseline data as there have been no reported studies of TDI in central India to this date.

Methods. A cross sectional study was carried out among 4000 children of 60 schools in Indore using multistage random sampling method. Examination of permanent incisor teeth was done in accordance with the modified Elli's and Davey Classification using a standard mouth mirror and probe. Subjects who had clinical evidence of trauma were interviewed for details of the injury event by using structured questionnaire. Chi square test was used to analyze the distribution of all the measurement in this study at the statistical significance of 0.05 .

Results. Among the 4000 children of 60 schools examined, 10.2\% experienced TDI. 68.38\% boys experienced TDI, which was approximately twice as higher in females being $31.62 \%$. The most commonly affected teeth were maxillary central incisors. A higher number of children with incisal overjet greater than $3 \mathrm{~mm}$ had TDI than those with less than $3 \mathrm{~mm}$, although this difference was not statistically significant. Lip closure incompetence was found to be more common in subjects having a TDI. Fall was the most common cause for TDI and place of occurrence was home. Most common type of fracture was class I and most of them were untreated.

Conclusion. The high level of dental trauma and low percentage of children with trauma seeking treatment stresses the need for increased awareness in Indore population.
\end{abstract}

Keywords: tooth injuries, incisors, fractures, oral health

\section{Introduction}

One of the greatest assets a person can have is a "smile" that shows beautiful, natural teeth. An untreated and unsightly fracture of an anterior tooth can affect the behavior of a child, his progress in school, and can have more impact on their daily living. Dental caries and periodontal disease are leading causes of tooth loss. Apart from this, tooth loss also occurs due to trauma, which may

Manuscript received: 22.09.2017

Received in revised form: 21.01.2018

Accepted: 13.02.2018

Address for correspondence: dr.preenejuneja@gmail.com be caused by violence, accidents, falls and sport-related activities. The majority of dental injuries involve anterior teeth [1]. Epidemiological studies indicate that dental trauma is a significant problem in young people and that in the near future, the incidence of trauma will exceed that of dental caries and periodontal disease in young population. Studies reported frequencies ranging from 9.4\%-41.6\% in primary dentition [2]. Traumatic injuries in permanent teeth have been reported to have a prevalence rate between $6.1 \%$ to $58.6 \%$. The great variation in reported rates can be attributed to a number of different factors, including 
types of study, trauma classification, methodology, study size and population, geographical location and differences in cultural behavior [3]. Many studies on prevalence of Traumatic dental injuries are reported in the literature in India $[4,5,6,7,8,9,10,11]$. Traumatic dental injuries seen to be a serious dental public health problem among children in deprived areas. Thus there is an urgent need to collect the local data on dental injuries in order to obtain a more comprehensive picture of the dental health.

No published literature is available on etiology and the prevalence of traumatic injuries to anterior teeth for Indore children. Hence, this study was carried to determine the prevalence of fractured anterior teeth and its relation with predisposing risk factors among 8-15 years school children and strategies for prevention and policy are also suggested.

\section{Material and methods}

\section{Ethical approval}

Before the commencement of the study, permission from the ethical committee of Sri Aurobindo College of Dentistry was obtained for the examination of school children. Formal letters were sent to the selected schools along with the required authorities permission. All parents or legal guardians were asked to sign a written informed consent form. The written consent explained about the aims, characteristics and importance of the study. Negative consent was adopted, without any prejudice towards the children who had opted not to participate.

\section{The study design and population}

A cross-sectional study was carried out through questionnaire \& clinical examination of the upper and lower permanent incisors (eight teeth) in 8 to 15 years old children regularly attending private, public school in Indore (Madhya Pradesh), a central region in India.

\section{Sample size and sampling procedure}

The prevalence of dental injury of average 10\% (dependent variable) was pre estimated for the calculation of sample size referring to various studies [4,12]. According to the sample size equation the minimum sample size to satisfy the requirement was estimated to be 3418 to achieve a level of precision with a standard error of 5\%. A 95\% confidence interval was used for the calculation of the sample size. The required sample size was increased to 4000 to avoid Type II sampling error, and to decrease the effect of confounding variables and increase the precision of the study (in order to compensate for potential refusals). The sample included 2058 boys and 1534 girls.

A correction factor of 1.5 was applied to increase the precision as a multistage random sampling method was adopted rather than random sampling.

The schools were selected on the basis of location. The Map of Indore city was adopted and was divided into five zones namely, north, east, west, south and central zone. In the first stage a list of schools including their address, phone numbers, number of classes and total number of children was obtained; in the second stage schools were distributed by areas i.e. private and public schools; in the third stage equal number of schools were randomly selected from each area. As the number of children differed from school to school equal probability schemes was adopted by sampling with a probability proportional to school size.

\section{The questionnaire}

A short questionnaire about age, sex, risk factors, cause of injury, type of injury, and the tooth involved. Only children with a positive history of traumatic dental injury and who had experienced injury not more than once were included in the study. Students who had lost anterior tooth because of dental caries, root fracture, marked dental fluorosis and physically, mentally or medically compromised children were excluded from the study.

\section{Diagnostic criteria of traumatic dental injuries}

Children were seated on a chair and ADA type III examination was carried out using a mouth mirror and Williams Probe under adequate illumination. Strict infection control measures were used. All dental examinations were carried out by a single dentist who had participated in a training and calibration exercise on the criteria used to identify dental injuries. During this phase the results were found to be reliable (kappa $=0.95$ ). The teeth were examined by direct vision. Neither vitality nor radiographs were used to assess the extent of the fractured teeth. The examination was conducted in a uniform fashion beginning from the maxillary right quadrant to the mandibular in a clockwise direction. Modified version of Ellis classification was used (Ellis RG, 1970) [13] (Table I). It is a simplified classification and has been used in a previous study for recording dental trauma and as we did not evaluate injuries to the alveolar socket and fractures of the jaws or laceration of the gingival or oral mucosa, we preferred to use this simple classification instead of Andreasen's classification. Overjet was measured using a Community Periodontal Index probe which was dichotomised to $\leq 3 \mathrm{~mm}$ and $>3 \mathrm{~mm}$ during the analysis. Overjet was measured from the linguo-incisal line angle of the most prominent maxillary incisor to the buccal aspect of the corresponding mandibular incisors. CPI probe was used to measure the degree of overjet as described by the 1997 WHO basic Oral Health Survey Guidelines. Lip coverage was recorded according to the criteria adopted by Burden. If the lip covered the upper incisors during the rest position, lip coverage was rated as adequate. If the greater part of the upper incisors was exposed or lip strain was evident upon closure, lip coverage was rated as inadequate [14].

Data analysis included descriptive statistics (frequency distribution and cross tabulation). The data were analysed using SPSS version 20. A chi square test was used for bivariate analysis and multiple logistic regression was performed. Statistical significance for the association between the occurrence of dental injuries and gender, incisal overjet and lip coverage was determined using multiple logistic regression. The level of significance was $p<0.05$. 
Table I. The modified Ellis classification and criteria and scoring for TDI (Ellis RG et al, 1970 [13]).

\begin{tabular}{|l|l|l|}
\hline Code & Criteria & Description \\
\hline 0 & No Trauma & \\
\hline 1 & Enamel fracture & Simple fracture of crown, enamel only; involving little or no dentine \\
\hline 2 & Enamel and dentine fracture & Extensive fracture of the crown involving considerable dentine but with no pulp \\
\hline 3 & Enamel and dentine fracture with pulp & Extensive fracture of the crown involving considerable dentine and exposing dental pulp \\
\hline 4 & Non- vital tooth with discoloration & Traumatized tooth that is non vital, and is discoloured, with or without loss crown structure \\
\hline 5 & Displacement & Extrusion, intrusion or lateral displacement \\
\hline 6 & Total tooth loss & Absence of tooth due to complete ex-articulation \\
\hline 7 & Fracture and restoration & Restored tooth with composite or crown following fracture of crown \\
\hline
\end{tabular}

\section{Results}

\section{Prevalence}

A total of 4000 children were examined. The response rate was $100 \%$ and the sample size satisfied the requirements. The group consisted of 2337 boys (58.4\%) and $1663(41.6 \%)$ girls. 489 were 8 years old, 508 were 9 years old, 460 were 10 years old, 672 were 11 years old 436 were 12 years old, 490 were 13 years old, 490 were 14 years old, 455 were 15 years old.

Table II summarizes the sample distribution of TDI according to age and gender. Peak occurrence of trauma was found at 15 years of age.

The prevalence of TDI of permanent anterior teeth was $10.2 \%$, affecting 408 school children of both the genders. $279(68.38 \%)$ of these were boys and $129(31.62 \%)$ girls. A statistically significant difference between genders was found: boys were 1.75 times $(95 \% \mathrm{CI}=1.397-2.194)$ more prone to traumatic dental injuries compared to girls $(\mathrm{p}<0.05)$ as illustrated in Table III.

$281(68.87 \%)$ children had one injured teeth while 127 $(31.13 \%)$ had two injured teeth. Maxillary central incisors $(73.27 \%)$ were the most commonly affected fractured teeth followed by maxillary lateral incisor $(21.5 \%)$.

Out of two injured teeth both maxillary central incisors were involved in $70.87 \%$ of children, maxillary central and lateral incisors were involved in $25.98 \%$, both mandibular lateral incisors were involved in 3.14\%.

Table IV summarizes the frequency distribution of types of TDI in school children. Most common type of fractures were simple fracture of the crown involving little or no dentin (class I) which accounted for $51.4 \%$, followed by others. Using chi square test association was found to be statistically significant $(\mathrm{p}=0.05)$.

Table II. Prevalence of the traumatic injuries according to age and gender.

\begin{tabular}{|l|l|l|l|l|l|l|}
\hline Age & Males & Females & Total \\
\hline & TDI Absent & TDI Present & TDI Absent & TDI Present & TDI Absent & TDI Present \\
\hline 8 & 334 & 23 & 112 & 20 & 446 & 43 \\
\hline 9 & 251 & 45 & 200 & 12 & 451 & 57 \\
\hline 10 & 210 & 22 & 212 & 16 & 422 & 38 \\
\hline 11 & 402 & 40 & 210 & 20 & 612 & 60 \\
\hline 12 & 159 & 20 & 241 & 16 & 400 & 36 \\
\hline 13 & 229 & 47 & 200 & 14 & 429 & 61 \\
\hline 14 & 259 & 38 & 179 & 14 & 438 & 52 \\
\hline 15 & 214 & 44 & 180 & 17 & 394 & 61 \\
\hline Total & 2058 & 279 & 1534 & 129 & 3592 & 408 \\
\hline
\end{tabular}

Table III. Boys: girls ratio and prevalence of boys with anterior teeth fracture.

\begin{tabular}{|l|l|l|c|c|c|}
\hline Sex & Number of children examined & Number of children with TDI & Boys: Girls & Prevalence & P value \\
\cline { 1 - 4 } Boys & 2337 & 279 & \multirow{2}{*}{$2.1: 1$} & \multirow{2}{*}{$10.2 \%$} & .01 \\
\hline Girls & 1663 & 129 & & & \\
\hline Total & 4000 & 408 & & & \\
\hline
\end{tabular}

Table IV. Frequency distribution of types of traumatic dental injuries in school children.

\begin{tabular}{|l|l|l|l|l|l|l|l|}
\hline $\begin{array}{l}\text { Nature of } \\
\text { trauma }\end{array}$ & $\begin{array}{l}\text { Number of } \\
\text { injured teeth }\end{array}$ & $\begin{array}{l}\text { Percentage of } \\
\text { injured teeth }\end{array}$ & $\begin{array}{l}\text { Boys with injured } \\
\text { teeth }\end{array}$ & Percentage & $\begin{array}{l}\text { Girls with injured } \\
\text { teeth }\end{array}$ & Percentage & P value \\
\hline Class I & 275 & 51.41 & 180 & 51.57 & 95 & 51.07 & .05 \\
\hline Class II & 203 & 37.94 & 139 & 39.82 & 64 & 34.40 \\
\hline Class III & 57 & 10.65 & 30 & 8.56 & 27 & 14.51 \\
\hline Total & 535 & 100 & 349 & 100 & 186 & 100 \\
\hline
\end{tabular}




\section{Causes and place of TDI}

Fall was the most common cause of injury (55.6\%) for the majority of children as illustrated in Table V.

The majority of the injuries took place at home $(67.2 \%)$, followed by school $(25.4 \%)$ and other places (7.4\%) such as streets, playgrounds etc. as shown in Table VI. With $\mathrm{p}$ value of .001 , association of place of occurrence of traumatic injury was significant.

\section{Risk factors}

Table VII illustrates the results of the logistic regression which showed a significant association between dental injuries and gender, size of the overjet and type of lip coverage. Among the subjects with an overjet of $3 \mathrm{~mm}$ or more, $13.4 \%$ of the subjects had TDI, as compared to $9.6 \%$ subjects with TDI amongst those with an overjet under 3 $\mathrm{mm}(\mathrm{p}<.05)$. The results of multiple logistic regression showed that children with an overjet size $>3 \mathrm{~mm}$ were $(95 \% \mathrm{CI}=.526-.889)$ more likely to present with a dental injury than children with an overjet size $<3 \mathrm{~mm}$. The odds ratio for increased overjet was 0.684 .

Subjects with incompetent lip closure had a significantly higher number of TDI than those with competent lip closure $(\mathrm{p}<0.05)$.

\section{Treatment modality}

Only $9.3 \%$ of the affected children had sought treatment for their dental injuries, compared to the $42.89 \%$ who did not receive any treatment as they had no problem with the TDI. Another important finding was that $24.5 \%$ did not receive any treatment as they were unaware of the injury. The other reason for not receiving treatment were disinterested parents (12.25\%), high cost (6.12\%) and fear of pain $(4.90 \%)$.

Table V. Distribution and percentage of children with traumatized anterior teeth according to the place of occurrence of trauma.

\begin{tabular}{|l|l|l|l|l|l|l|l|}
\hline Etiology & \multicolumn{2}{|l|}{$\begin{array}{l}\text { Children with injured teeth } \\
\text { Number Percentage }\end{array}$} & \multicolumn{2}{l}{$\begin{array}{l}\text { Boys with injured teeth } \\
\text { Number Percentage }\end{array}$} & $\begin{array}{l}\text { Girls with injured teeth } \\
\text { Number Percentage }\end{array}$ & \multirow{2}{*}{ P value } \\
\hline Fall & 227 & 55.64 & 155 & 55.56 & 72 & 55.81 \\
\hline Sports & 82 & 20.09 & 60 & 21.51 & 22 & 17.05 \\
\hline Accident & 65 & 15.93 & 45 & 16.13 & 20 & 15.50 \\
\hline Collision & 22 & 5.3 & 12 & 4.30 & 10 & 7.76 \\
\hline Biting & 12 & 2.95 & 07 & 2.50 & 05 & 3.88 \\
\hline Total & 408 & 100 & 279 & 100 & 129 & 100 \\
\hline
\end{tabular}

Table VI. Distribution and percentage of children with traumatized anterior teeth according to the place of injury.

\begin{tabular}{|c|c|c|c|c|c|c|c|}
\hline Place & \multicolumn{2}{|c|}{$\begin{array}{l}\text { Children with Injured teeth } \\
\text { Number Percentage }\end{array}$} & \multicolumn{2}{|c|}{$\begin{array}{l}\text { Boys with injured teeth } \\
\text { Number Percentage }\end{array}$} & \multicolumn{2}{|c|}{$\begin{array}{l}\text { Girls with injured teeth } \\
\text { Number Percentage }\end{array}$} & \multirow{2}{*}{$\begin{array}{l}\mathrm{P} \text { value } \\
.001\end{array}$} \\
\hline Home & 274 & 67.16 & 203 & 72.75 & 71 & 55.03 & \\
\hline School & 104 & 25.49 & 60 & 22.50 & 44 & 34.10 & \\
\hline Others & 30 & 7.35 & 16 & 5.73 & 14 & 10.85 & \\
\hline Total & 408 & 100 & 279 & 100 & 129 & 100 & \\
\hline
\end{tabular}

Table VII. Results of multiple logistic regression of gender, size of the incisal overjet and type of lip coverage for TDI in 4000 school children in Indore.

\begin{tabular}{|c|c|c|c|c|c|c|}
\hline & \multicolumn{4}{|c|}{ Traumatic dental injury } & \multirow[t]{3}{*}{ P value } & \multirow[t]{3}{*}{ OR and CI,95\% } \\
\hline & \multicolumn{2}{|l|}{ No } & \multicolumn{2}{|l|}{ Yes } & & \\
\hline & $\mathrm{N}$ & $\%$ & $\mathrm{~N}$ & $\%$ & & \\
\hline \multirow{2}{*}{$\begin{array}{l}\text { Gender Girls } \\
\text { Boys }\end{array}$} & 1534 & $92.24 \%$ & 129 & $7.76 \%$ & \multirow[t]{2}{*}{.01} & \multirow{2}{*}{ (1.751) 1.397-2.194 } \\
\hline & 2058 & $88.06 \%$ & 279 & $11.94 \%$ & & \\
\hline \multirow{2}{*}{$\begin{array}{l}\text { Overjet }<3 \mathrm{~mm} \\
>3 \mathrm{~mm}\end{array}$} & 2984 & $90.4 \%$ & 314 & $9.6 \%$ & \multirow[t]{2}{*}{.01} & \multirow[t]{2}{*}{$(.684) .526-.889$} \\
\hline & 608 & $86.6 \%$ & 94 & $13.4 \%$ & & \\
\hline \multirow{2}{*}{$\begin{array}{l}\text { Lip coverage Adequate } \\
\text { Inadequate }\end{array}$} & 3282 & $90.2 \%$ & 359 & $9.8 \%$ & \multirow[t]{2}{*}{.01} & \multirow[t]{2}{*}{ (1.473) $1.043-2.080$} \\
\hline & 310 & $86.4 \%$ & 49 & $13.6 \%$ & & \\
\hline
\end{tabular}




\section{Discussion}

Traumatic dental injury is not a result of disease but a consequence of certain factors that will accumulate throughout life if not properly treated [8]. For this study the age between 8-15 years was chosen, as during this period there is maximum physiological growth and development and children are actively involved in lot of outdoor activities. The study found a prevalence of $10.2 \%$ of traumatic dental injuries to the permanent incisors of 8-15 year old school children in Indore. Studies conducted among adolescents in India reported prevalence from $4-35 \%$ [15]. Variations in prevalence of TDI have been attributed to the environment, the study sites, examination methods, type of dentition and TDI classification used [16].

The reported prevalence in our study is lower than reported $14.9 \%$ and $13.8 \%$ by Baldava et al., 2007 and Gupta et al., 2002 respectively [17,18]. The $8.79 \%$ and $4.1 \%$ prevalence noted is lower as compared to other studies $[8,19]$. It is inappropriate, for instance, to compare figures found in clinic and hospital based studies with population based studies. It is known that clinic and hospital based studies provide less epidemiological evidence than population based studies.

In this study, out of 408 subjects 279 boys and 129 girls were affected. This may be attributed to behavioral factors, with the boys tending to be more energetic and inclined towards vigorous outdoor activities, contact sports and violence as compared to girls. The fact that boys had suffered more traumatic injuries may be also explained by cultural factors and social capital $[12,20]$. A difference in frequency of dental injuries was observed between boys and girls with a ratio of 2:1. Our finding of a greater frequency of traumatic dental injuries in boys is supported by a majority of previous studies $[12,15,21,22,23]$. But no significant difference was observed by some studies $[1,24,25]$. Some studies indicated an increasing trend of dental trauma in girls which may be due to increased participation of girls in sports and physical leisure activities formerly restricted to boys. Besides, girls can be exposed to traffic accidents and violence in the same way as boys [26]. Behavior is crucial when considering the occurrence of traumatic dental injuries in children and adolescents. Children with behavioral problems are more likely to be excitable, reckless and more willing to take risks, which increases their chance of getting into situations that result in injury [27].

This study showed that maxillary teeth are more frequently traumatized than mandibular teeth; this is generally supported by existing literature $[1,7,19,21,22]$. The most frequently affected teeth are maxillary central incisors. This probably relates to the vulnerable position of the maxillary incisors. Also injury to maxillary incisors is more frequent than mandibular incisors because blow to mandibular teeth are dissipated due to non rigid connection of mandible to the cranial base [8].
Out of $10.8 \%$ subjects, $3.71 \%$ had two injured teeth and $7.09 \%$ had one injured teeth, which is in agreement with other reported studies $[1,28,29,30]$.

The cause of the injury may vary according to sex, age, climate and socioeconomic status of the children. In our study the most common cause of traumatic injuries was "Fall" (55.6\%) followed by sports to be the main etiological factor of dental trauma which is similar to other reported studies [1,8,9,16,21,22,31,32,33,34,35]. Factors such as falls and collisions are broad categories and could conceal the real causes of such injuries, for instance various forms of violence. During the past 30 years, the number of etiologies has increased dramatically in the scientific literature. According to a study conducted by Baghdady in Sudan and Iraq, (1981) violence (36\% in Iraq and $71 \%$ in Sudan) was the main cause of TDI. In contrast, Uji and Teramoto in Japan, and Blinkhorn in the UK reported sports to be among the main causes of TDI in teenagers. In the Nicolau et al. study of 2001 the proportion of the unknown cause of TDIs was $40 \%$. If the number of unknown causes had been less there would probably have been a greater distribution of other causes. Thus the conclusion is that it is difficult to compare countries, but it is probably possible within a given country. The use of accepted etiological factors would lead to a more consistent comparison of studies $[3,31]$.

The majority of the injuries took place at home followed by school and other places such as playgrounds, streets etc. Similar results were obtained by other studies $[15,16]$. The most frequent activities undertaken by the children at the time of the accident were leisure (72.1\%) and sports activities (11.6\%). Unknown location was reported by $37.8 \%$ of school children with TDI [36]. The majority of injuries which occurred at home could be due to the fact that children (especially girls) spend more time at home rather than school and playground or perhaps the injuries occurred at home during vacation. 8 Although the majority of traumatic dental injuries occur at home, the role of the school environment should also be emphasized because of children's involvement in physical and social activities have shown that the level of commitment to health and safety at school was strongly associated with dental trauma [37]. In large cities, there are probably greater numbers of students in schools, more children in classrooms and schools located in slum areas, where hypothetically, at least, levels of school commitment to health and safety may be lower [36]. Moreover, schools are considered appropriate settings to begin promoting oral health and the prevention of dental trauma, because there are more than one billion children in schools all over the world, where teachers, school staff, parents and community are also involved. In view of our findings, it is also essential to consider strategies in the home environment, possibly by involving parents more closely in local campaigns and programmes to increase social awareness on the prevention 
of dental injury [16].

The most common type of injury was found to be enamel fracture, similar to that reported by other author $[1,21,24,25,35,38]$. No cases of avulsion were reported in the present study.

The age at which children are more prone to traumatic injuries should be identified so that preventive measures should be directed to protect the risk population to a considerable extent. In this study the peak age to sustain injury was found to be 15 years. Traumatic dental injuries increased with increasing age. The possible explanation for this is that as the child grows older there is an increase in injuries arising from sports, violence, and collision and biting on hard object. Some other studies in the previous year's showed similar results $[1,15,28,33]$.

In this study, $16.6 \%$ of children with increased overjet $(>3 \mathrm{~mm}$ ) sustained injury, while $13.6 \%$ of normal overjet children sustained injury, indicating that a relationship exists between a larger overjet and greater susceptibility to dental injury, although this was not found to be statistically significant. In some studies the definition of protrusion begins at $>3-3.5 \mathrm{~mm}[14,36]$, whereas in others at $>5.0 \mathrm{~mm}$ which makes it difficult to compare studies [12,22].

This may be due to the small number of children with overjet $>3 \mathrm{~mm}$ in this study. Upon reviewing the literature, many Indian studies $[1,6,8]$. In the present study $3 \mathrm{~mm}$ was taken as the criterion as it showed significant increase in TDI. This finding concurred with other studies who reported that children with an overjet equal to or greater than $3.0 \mathrm{~mm}$ were 1.32 times more likely to experience a dental trauma than children with an overjet lower than 3.0 $\mathrm{mm}$. This finding is contrary to that of Marcenes et al. 1999 $[12,30,39]$.

Incompetent lip closure was significantly related to traumatic dental injury. Inadequate lip coverage was identified as the most powerful independent predictor for occurrence of anterior-tooth injuries. This is in agreement with the findings of many other studies $[12,14,17]$.

Our study showed that only $9.3 \%$ of the affected children had received treatment for trauma. It was prominently seen that even for complicated fractures involving pulp discoloration, children had not received any treatment. The largest proportion of unmet treatment need was represented by class I fractures $(51.41 \%)$. Therefore there is a high unmet treatment need. Lack of adequate knowledge and proper motivation compounded by limitations imposed due to socioeconomic constraints could explain the high percentage of untreated injuries. Because of the impact of traumatic dental injury in children daily life is great, in terms of physical and psychological discomfort and pain there is need for specific public health policies that seek to decrease the high prevalence of traumatic dental injury among school children and minimize their effects on children's quality of life.

Preventive strategies need to address the underlying determinants of oral conditions to achieve sustainable improvements in oral health and to reduce inequalities. A guiding concern for injury prevention practitioners and researchers is why and how childhood injuries occur [16]. Although some sports-related traumatic injuries are unavoidable, most can be prevented. Helmets, facemasks, and mouth guards have been shown to reduce both the frequency and severity of dental and orofacial trauma [36].

The present study followed a cross sectional design and a retrospective collection of data on traumatic dental injuries. One of the shortcomings is the accuracy of a patient's history which is particularly true in case of children. Although this is a limitation of this study, cross sectional studies are important tools to identify risk factors to be included in further longitudinal assessment.

Unfortunately, there is a lacuna in our evidencebased knowledge on prevention of dental trauma. Many do believe that a mouth guard will protect the teeth and even the brain, but without good randomized clinical trial study, the evidence supporting that belief is weak at best. In the meantime, emphasis should be placed on education by using the most contemporary ways possible, such as the Internet and apps, on how to prevent as well as how to respond to a dental injury. Pedagogical studies on how best to approach this are also sorely lacking and would be most interesting [3].

\section{Conclusion}

The prevalence of TDI in this population was found to be $10.8 \%$. Most common type of fracture was class I and most of them were untreated (90\%). This was a surprising observation as the city has five dental institutions and 500 practising dentists in Indore city. There is need to create dental awareness through dental education amongst Indore school going children. An effort can be made to reduce the prevalence of traumatic injuries by taking into consideration the following measures-

- The use of intraoral and extraoral devices which protect the teeth and face from trauma.

- The knowledge of dental practitioner should be improved through continuing education in order to minimize the sequelae of traumatic dental injury.

- Educational programmes whereby the children and their parents are given information regarding the prevention and treatment aspects of this commonly occurring condition.

Furthermore, to achieve adequate awareness, posters and educational handouts or brochures should be distributed in schools.

\section{References}

1. Kumar A, Bansal V, Veeresha KL, Sogi GM. Prevalence of traumatic dental injuries among 12- to 15-year-old schoolchildren in Ambala district, Haryana, India. Oral Health Prev Dent. 2011;9:301-305.

2. Norton E, O'Connell AC. Traumatic dental injuries and their 
association with malocclusion in the primary dentition of Irish children. Dent Traumatol. 2012;28(1):81-86.

3. Glendor U. Aetiology and risk factors related to traumatic dental injuries--a review of the literature. Dent Traumatol. 2009;25:19-31.

4. Rai SB, Munshi AK. Traumatic injuries to the anterior teeth among South Kanara school children--a prevalence study. J Indian Soc Pedod Prev Dent. 1998;16:44-51.

5. David J, Astrøm AN, Wang NJ. Factors associated with traumatic dental injuries among 12-year-old schoolchildren in South India. Dent Traumatol. 2009;25:500-505.

6. Gupta S, Kumar-Jindal S, Bansal M, Singla A. Prevalence of traumatic dental injuries and role of incisal overjet and inadequate lip coverage as risk factors among 4-15 years old government school children in Baddi-Barotiwala Area, Himachal Pradesh, India. Med Oral Patol Oral Cir Bucal. 2011;16:e960-e965.

7. Dhingra S, Marya CM, Avinash J,Gupta P, Nagpal R, Pruthi N. Prevalence and Risk Factors Associated with Trauma to Permanent Anterior Teeth in 12 to 15 Year Old School Going Children in Urban and Rural Areas of Faridabad, Haryana: A Comparative Study. International Journal of Clinical Preventive Dentistry 2012;8:89-95.

8. Patel MC, Sujan SG. The prevalence of traumatic dental injuries to permanent anterior teeth and its relation with predisposing risk factors among 8-13 years school children of Vadodara city: an epidemiological study. J Indian Soc Pedod Prev Dent. 2012;30:151-157.

9. Dua R, Sharma S. Prevalence, causes, and correlates of traumatic dental injuries among seven-to-twelve-year-old school children in Dera Bassi. Contemp Clin Dent. 2012;3:38-41.

10. Govindarajan M, Reddy VN, Ramalingam K, Durai KS, Rao PA, Prabhu A. Prevalence of traumatic dental injuries to the anterior teeth among three to thirteen-year-old school children of Tamilnadu. Contemp Clin Dent. 2012;3:164-167.

11. Murthy AK, Mallaiah P, Sanga R. Prevalence and Associated Factors of Traumatic Dental Injuries Among 5- to 16-year-old Schoolchildren in Bangalore City, India. Oral Health Prev Dent. 2014; 12:37-43.

12. Marcenes W, al Beiruti N, Tayfour D, Issa S. Epidemiology of traumatic injuries to the permanent incisors of 9-12-yearold schoolchildren in Damascus, Syria. Endod Dent Traumatol. 1999; 15:117-123.

13. Ellis RG, Davy KW. The classification and treatment of injuries to the teeth of children. 5th ed. Chicago: Yearbook Medical Publishers; 1970.

14. Burden DJ. An investigation of the association between overjet size, lip coverage, and traumatic injury to maxillary incisors. Eur J Orthod. 1995;17:513-517.

15. Kalaskar R, Tawani GS, Kalaskar A. Paediatric traumatic dental injuries in hospital of central India. a 2.5 year retrospective review. IJRID. 2013;3:1-10.

16. Naidoo S, Sheiham A, Tsakos G. Traumatic dental injuries of permanent incisors in 11- to 13-year-old South African schoolchildren. Dent Traumatol. 2009;25:224-228.

17. Baldava P, Anup N. Risk factors for traumatic dental injuries in an adolescent male population in India. J Contemp Dent Pract. 2007;8:35-42.

18. Gupta K, Tandon S, Prabhu D. Traumatic injuries to the incisors in children of South Kanara District. A prevalence study. J Indian Soc Pedod Prev Dent. 2002;20:107-113.

19. Nik-Hussein NN. Traumatic injuries to anterior teeth among schoolchildren in Malaysia. Dent Traumatol. 2001;17:149-152. 20. Pattussi MP, Hardy R, Sheiham A. Neighborhood social capital and dental injuries in Brazilian adolescents. Am J Public Health. 2006;96:1462-1468.

21. Ingle NA, Baratam N, Charania Z. prevalence and factors associated with traumatic dental injuries (TDI) to anterior teeth of 11-13 year old school going children of Maduravoyal, Chennai. J Oral Health Comm Dent. 2010;4(3):55-60.

22. Soriano EP, Caldas AF Jr, Góes PS. Risk factors related to traumatic dental injuries in Brazilian schoolchildren. Dent Traumatol. 2004;20:246-250.

23. Marcenes W, Murray S. Social deprivation and traumatic dental injuries among 14-year-old schoolchildren in Newham, London. Dent Traumatol. 2001;17:17-21.

24. García-Godoy F, Dipres FM, Lora IM, Vidal ED. Traumatic dental injuries in children from private and public schools. Community Dent Oral Epidemiol. 1986;14:287-290.

25. Traebert J, Peres MA, Blank V, Böell Rda S, Pietruza JA. Prevalence of traumatic dental injury and associated factors among12-year-old school children in Florianópolis, Brazil. Dent Traumatol. 2003;19:15-18.

26. Rocha MJ, Cardoso M. Traumatized permanent teeth in Brazilian children assisted at the Federal University of Santa Catarina, Brazil. Dent Traumatol. 2001;17:245-249.

27. Odoi R, Croucher R, Wong F, Marcenes W. The relationship between problem behaviour and traumatic dental injury amongst children aged 7-15 years old. Community Dent Oral Epidemiol. 2002;30:392-396.

28. Cortes MI, Marcenes W, Sheiham A. Prevalence and correlates of traumatic injuries to the permanent teeth of schoolchildren aged 9-14 years in Belo Horizonte, Brazil. Dent Traumatol. 2001;17:22-26.

29. Zerman N, Cavalleri G. Traumatic injuries to permanent incisors. Endod Dent Traumatol. 1993;9:61-64.

30. Petti S, Tarsitani G. Traumatic injuries to anterior teeth in Italian schoolchildren: prevalence and risk factors. Endod Dent Traumatol. 1996;12:294-297.

31. Nicolau B, Marcenes W, Sheiham A. Prevalence, causes and correlates of traumatic dental injuries among 13-year-olds in Brazil. Dent Traumatol. 2001;17:213-217.

32. García-Godoy FM. Prevalence and distribution of traumatic injuries to the permanent teeth of Dominican children from private schools. Community Dent Oral Epidemiol. 1984;12:136-139.

33. Cavalcanti AL, Bezerra PK, de Alencar CR, Moura C. Traumatic anterior dental injuries in 7- to 12-year-old Brazilian children. Dent Traumatol. 2009;25:198-202.

34. Adekoya-Sofowora CA, Adesina OA, Nasir WO, Oginni AO, Ugboko VI. Prevalence and causes of fractured permanent incisors in 12-year-old suburban Nigerian schoolchildren. Dent Traumatol. 2009;25:314-317.

35. Navabazam A, Farahani SS. Prevalence of traumatic injuries to maxillary permanent teeth in 9- to 14-year-old school children in Yazd, Iran. Dent Traumatol. 2010;26:154-157.

36. Traebert J, Bittencourt DD, Peres KG, Peres MA, de Lacerda JT, Marcenes W. Aetiology and rates of treatment of traumatic dental injuries among 12-year-old school children in a town in southern Brazil. Dent Traumatol. 2006;22:173-178.

37. Moysés ST, Moysés SJ, Watt RG, Sheiham A. Associations between health promoting schools' policies and indicators of oral health in Brazil. Health Promot Int. 2003;18:209-218.

38. Marcenes W, Zabot NE, Traebert J. Socio-economic correlates of 


\section{Original Research}

traumatic injuries to the permanent incisors in schoolchildren aged 12 years in Blumenau, Brazil. Dent Traumatol. 2001;17:222-226.

39. Hamdan MA, Rock WP. A study comparing the prevalence and distribution of traumatic dental injuries among 10-12-yearold children in an urban and in a rural area of Jordan. Int J Paediatr Dent. 1995;5:237-241. 